\title{
Investigating the Performance of Point to Multipoint Microwave Connectivity across Undulating Landscape during Rainfall
}

\author{
W. Nwankwo ${ }^{\mathrm{a}}$, K. E. Ukhurebor ${ }^{\mathrm{b}, *}$ \\ ${ }^{a}$ Software Engineering/Cyber Physical Lab, Department of Mathematics and Computer Science, Edo University Iyamho, P.M.B. 04 Auchi, Edo State, Nigeria \\ ${ }^{b}$ Climatic/Environmental/Telecommunication Physics Unit, Department of Physics, Edo University Iyamho, P.M.B. 04 Auchi, Edo State, Nigeria
}

\begin{abstract}
One of the most debated issues surrounding wireless connectivity is performance especially under different topographic and climatic scenarios. Performance has a direct relationship with throughput measured in terms of how well a given wireless connectivity provides consistent services over a given period compared to the wired alternative. Research has shown that wireless connectivity is constrained by significant physical components such as topography, weather conditions, propagation frequency, and distance. It is commonplace to see notable vendors of wireless network products make claims as to how their technologies are designed to remedy any signal degradation that may arise from the aforementioned physical elements. This paper is aimed at evaluating the performance of a point to multipoint connectivity using Ubiquiti's $5.8 \mathrm{GHz}$ Point to Multipoint Base Stations deployed within a landscape marked by series of undulating highlands and lowlands. In this experiment, a base station node is established with connectivity to two other nodes of same specifications with one node as the destination radio whereas the other acts as the control which is located on a table land. The nodes were separated by triangular distances of $3 \mathrm{~km}$ and network connectivity was maintained over thirty days during periods of rainfall. Packets sent and received across each node was carefully recorded. The results from the analysis showed that packet losses to and from the control node was significantly lower than that of the other node under same weather conditions.
\end{abstract}

Keywords: Landscape, Microwave, Nodes, Performance, Signal

Article History :

Received: 10 October 2019

Received in revised form: 27 October 2019

Accepted for publication: 29 October 2019

Published: 14 October 2019

(c)2019 Journal of the Nigerian Society of Physical Sciences. All rights reserved. Communicated by: O. J. Abimbola

\section{Introduction}

The technological breakthrough and development experienced in the field of wireless communication would not have been a success if references are not made to early scientists who did a lot of research in the field of wireless communications. Several inventions, theories and principles have been established in order to generate background foundation towards enormous advancement in the field of wireless communication [1].

${ }^{*}$ Corresponding author tel. no: +2348035383194

Email address: ukhurebor.kingsley@edouniversity.edu.ng (K. E. Ukhurebor )
These technologies continued to develop for over a century as people began to unravel the intricacies of telecommunications $[1,2,3]$. The development from $1 \mathrm{G}$ to $4 \mathrm{G}$ and now into LTE and beyond to $5 \mathrm{G}$ is a milestone. The dramatic development was not just experienced at an instance, but was seen as an improvement over an existing technology, a breakthrough in the field, and a transition from one to another with marked elemental upgrades. The evolution of mobile communication cannot be well understood if proper description of mobile communications, is not reviewed in respect of the overall technology, speed, frequency and system in numeric generations such as $3 \mathrm{G}, 4 \mathrm{G}$ or $5 \mathrm{G}$ [1]. Each generation has unique technologies 
that define it, and explains the differences throughout the evolution of mobile communications and what we can expect from the future generations of these technologies.

Wireless networks have some constraints to a wider option in enterprise network design and implementation. Such constraints include: attenuation, latency, interference, distortion of signals, as well as the effect of weather conditions specifically rainfall on performance and signal propagation [4-18].

But with consistent advancement in technology, some mechanisms have been integrated into high-end radios to help mitigate some of these constraints. However, there are still some debatable issues as to the performance of wireless networks under extreme weather conditions and unusual landscapes $[10,11$, 12].

The aim of this study is to investigate the performance of a $5 \mathrm{GHz}$ point-to-point and point-to-multipoint radios across undulating landscape during rainfall. We intend to achieve this aim by understudying the geography of the study area, which according to previous studies [1-12], have remarkable topographic characteristics with emphasis on the distribution of weather conditions and signal propagation. We would attempt to determine the propagation and monitor the behaviour of radio signals within the $5 \mathrm{GHz}$ frequency band from one point to another having regard to the undulating lowlands and highlands during rainfall. Appropriate comparison on performance of same radio specifications under normal weather conditions on lowlands would also be considered in this study.

\section{Review of Related Works}

Indisputably, movement of vegetation structures introduces an adverse environment for high frequency radio wave propagation [10].

Hashim et al., [19], examines a series of vegetation scattering measurement campaigns during various wind conditions. Their measurements were divided into controlled and outdoor environments. The controlled environment measurements were conducted in an anechoic chamber at 0.9,2.0,12.0 and 17.0 GHz., while the outdoor measurements were carried out at $1.8 \mathrm{GHz}$, as well as recording of a transmitted signal originating from an existing digital cellular system (DCS-1800) base station. Their results were presented in terms of first-order and second-order statistics. From their analysis, the received signal behaviour was highly wind dependent, especially when the environment is changing from calm to a windy condition. The signal fastfading was found to be Rician distributed and an empirical model of the k-factor variation over wind speed were also presented in their study.

In the study carried out by Perras et al., [20], they compared the various temporal characteristics of radio channels for a broad range of frequencies, including 2.45, 5.25, 29.0 and 60.0 in various vegetation and weather conditions. A considerable number of data points, were in excess of 1.9 billion at 500 samples per second (equivalent to 45 days) was collected and analysed for three particular types of channels (foliated deciduous trees, non-foliated deciduous trees and coniferous trees).
The radio channels were statistically analysed and the resulting probability density functions (PDFs) and cumulated density functions CDFs) were compared with existing models. Furthermore, wind speeds and rain precipitation were correlated with the power samples, this was done in order to consider RF propagation dependencies. Second order statistics was derived including level crossing rate (LCR) and average facie duration (AFD). The power profile was analysed for spectral components. The frequency characteristics of the RF propagation channel were also evaluated. They also presented the channelspecific RF propagation attributes.

Pellet et al., [21], used a fixed terrestrial broadband wireless system such as Multipoint Microwave Distribution System (MMDS) which is a cost-effective solution for cable coverage to the immediate surrounding rural area. The wireless system was operated with the existing cable headend and the same subscriber-end cable modem. The system works well with clear line-of-sight transmit/receive antennas. However, in nearline-of-sight transmission where a few foliated trees block the line-of-sight, signal distortion were experienced, especially under conditions of high wind. They argued, that the motion of the trees was responsible for the huge and rapid signal fading. Their measurements were taken on fixed wireless paths blocked with a few trees in the vicinity of the receive antenna. Fading characteristics of a $6 \mathrm{MHz}$ channel centred at about $2.6 \mathrm{GHz}$ were provided. The fades were mostly flat across the band but with some frequency selective fading. Fading rates under windy conditions ranged from 0.5 to 2.0 fades/second. The slope of the fades occasionally reached $50 \mathrm{~dB} /$ second.

Dal Bello et al., [22], carried out their studies on propagation in an urban forested park area, their aim was to investigate the statistical nature of the time fading for frequencies ranging from $0.9 \mathrm{GHz}$ to $1.8 \mathrm{GHz}$, as well as to examine the range dependence and the base station height gain. They used a received signal of around $30 s$ intervals for a stationary mobile to design the distribution functions for the fading. According to them, the distribution could be approximated by a Rician distribution, whose $\mathrm{K}$-factor was found to depend on transmitter height.

Cuiñas et al., [23], reported that the presence of vegetation in the radio channel could affect the coverage areas of cellular mobile phone systems. They argued that the various components of a tree have influence in the performance of the radio system. Although, the trunk is commonly in a fixed and stable location, the leaves could be in continuous movement as a result wind. Accordingly, the time variation which can be correlated with the wind speed and direction, could strongly modify the attenuation and scattering effects of the trees on the radio channel performance. Their study presents the results (both long-term and short-term) of a measurement campaign of scattering and attenuation effects of isolated trees, under the action of artificial wind of different controlled speeds and directions. They show that the median effect of the presence of a tree is the induction of higher attenuation in the shadow areas and a new distribution of the scattering pattern all around the specimen. But, the wind on the leaves forces their movement and an increment in the time variation around the median received power values.

Zennaro et al., [24], revisited the issue of link quality in 
Wireless Sensor Networks (WSN). They studied the temporal and energy characteristics of a $24 \mathrm{GHz}$ sensor network in an outdoor environment using different values of output power and sampling period. They analysed battery behaviour in motes placed at different distances and reported that farther motes have a shorter battery life. They suggested that when deployed in the real world, the sampling periods of sensor networks be adjusted according to distance to normalize battery lifetime and a more accurate energy-aware routing protocol be developed.

According to Zhao et al., [25], wireless sensor networks promise fine-grain monitoring in a wide variety of environments. Many of these environments (like indoor environments or habitats) can be harsh for wireless communication. From a networking perspective, the fundamental aspect of wireless communication is the packet delivery performance (the spatio-temporal characteristics of packet loss and its environmental dependence). These factors would severely have impact on the performance of data acquisition from these networks. Their study was centred on a systematic medium-scale (up to sixty nodes) measurement of packet delivery in three different environments (an indoor office building, a habitat with moderate foliage and an open parking lot). Their results would have interesting implications for the design and evaluation of routing and mediumaccess protocols for sensor networks.

Puccinelli and haenggi [26], reported that multipath fading severely contributes to the unreliability of wireless links, causing fairly huge deviations from link quality predictions based on path loss models. Accordingly, its impact on wireless sensor networks is considerable. Although, analytical models provide a probabilistic description, multipath fading is a deterministic phenomenon. Moreover, in the case of static nodes, fading is time-invariant. They illustrated its spatial nature with experimental evidence obtained using lower-end sensing node hardware. They also show the limitations of the supposed immunity of wideband radios to multipath fading in indoor deployments.

The works of Ukhurebor et al., [27] and Ukhurebor and Umukoro [28] dealt extensively on the effects of some essential meteorological variables such as temperature, relative humidity and mean sea level pressure on the Ultra High Frequency (UHF) and Very High Frequency (VHF) radio signals. They stated that the radio signals from both the UHF and VHF television stations were directly proportional to the temperature, inversely proportional to the relative humidity and no defined pattern of proportionality with the mean sea level pressure. They argued that, the radio signals from the UHF television station were seen to be mostly affected by these weather variables. These effects according to them were more pronounced during the months with high relative humidity compared with the months with lower relative humidity.

According to [4]-[12], signal attenuation caused by rainfall, is a major challenge to microwave satellite communication especially at frequencies above $10 \mathrm{GHz}$. In several occasions, they cause signals unavailability. Rainfall attenuation predictions have become one of the vital considerations while setting up a satellite communication link [4] - [12]. In their respective studies, rainfall attenuation models, cumulative distribution curves and other analytical tools for successful prediction of rain attenuation were presented.

Basically, this study focussed on comprehensive evaluation of the performance and operation of $5 \mathrm{GHz}$ microwave radios during propagation and transmission of signals across undulating land areas taking into consideration the effect of weather in such circumstances [29]. Apparently, the results obtained offered some additional and novel insight on the effects of topography on the propagation of signals under certain weather conditions even where high frequency radios are employed.

\section{Materials and Methods}

The hierarchical approach to network design and implementation was adopted in this study. The hierarchical approach stipulates that a network be structured in such a way as to categorize similar functions into a layer and separate each layer from other layers, while ensuring communication among the different layers [4] - [12]. Each layer focuses on specific functions. The advantages of the hierarchical approach are notable, which include:

i. Enables the network planner or designer to identify and make proper choice of the right equipment for the design and implementation of each layer.

ii. Ensures proper evaluation of features that makes up the layers.

iii. Suitability for network designs of varying sizes and requirements.

In a hierarchical network the entire network is segmented into discrete layers. Each layer, or tier, provides specific functions that define its role within the overall network. This helps to optimize and select the right network hardware, software and features to perform specific roles in the network. Three main layers are recognized: Access, Distribution, and Core layers respectively.

\subsection{Hardware}

i. Three units of Ubiquiti rocket M5 point to multi-point (PtmP) base stations. The specification of the radios is: $5-5.83 \mathrm{GHz}$ spectrum, hi-power $2 \times 2$ MIMO TDMA AirMAX, Powersupply: $24 \mathrm{~V}, 1 \mathrm{~A}$ POE.

ii. Router (Huawei 1200 series).

iii. Switch (S5700 8-port).

iv. Cat-6 shielded twisted pair cable ( $40 \mathrm{~m}$ crimped cables).

v. Three computer systems with same specifications: HP Probook $6450 \mathrm{~b}$, intel R core ${ }^{\mathrm{TM}}$ i5 CPU (a) $2.40 \mathrm{GHZ}$, running Microsoft Windows 10 professional operating system.

vi. Infinix S4 Smart phone with Android 9.0, GPS coordinate and elevation apps respectively.

\subsection{Software}

i. Wireshark 3.0.5(Network packet analyzer)

ii. Enterprise Network Simulation Platform (eNSP)

iii. Microsoft Visio 2010

iv. IBM SPSS v.24

v. Ubiquiti Unifi controller software 


\subsection{Study Area}

This study was conducted in Iyamho community, a small town in Etsako West Local Government of Edo State, Nigeria. Iyamho is host to the fast-growing model University, Edo University Iyamho. It has approximately 5,000 inhabitants who are mostly rural dwellers. However, since the establishment of the University, the community is rapidly transforming to a beautiful semi-urban centre following the influx of workers, visitors and students. Consequent upon the foregoing, the town is witnessing an upsurge of modern communication infrastructure amidst other notable capital infrastructure such as police barracks, community health clinics and private-owned businesses. In the area of communication, there is relatively a heavy presence of mobile network base stations which have given rise to increased growth in the use of the Internet. It is presumably estimated that $55 \%$ of the population are active users of the internet. Geographically, Iyamho is located on latitude $7.07^{\circ} \mathrm{N}$ and longitude $6.27^{\circ} \mathrm{E}$ with an elevation of about $188 \mathrm{~m}$ above sea level $[16,17,18]$. Like other tropical areas of Southern Nigeria, Iyamho enjoys two seasons often categorized as rainy and dry seasons. It enjoys a Savannah vegetation. According to Ukhurebor et al., [17], its topography is marked with undulating and table lands. Figure 1 shows the aerial view of the community.

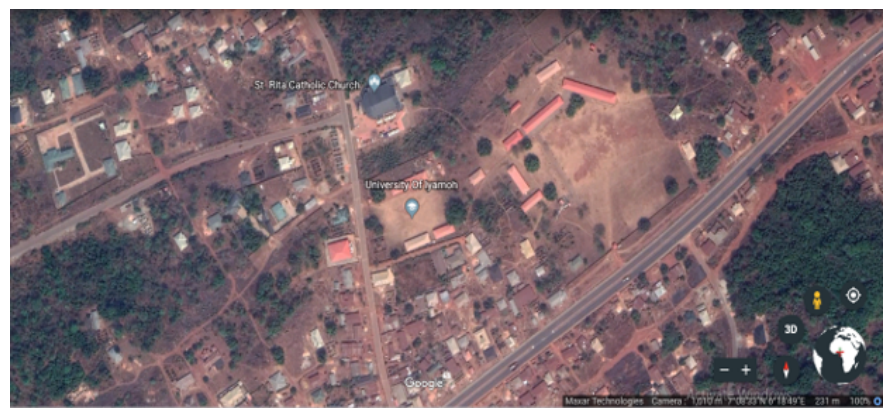

Figure 1: Aerial View of Iyamho, EtsakoWest of Edo State, Nigeria (Source: Google Earth).

\subsection{Design of Experiment}

The experiment involved three locations which were marked as follows:

Primary Station (the Base Station) is located at the Faculty of Science, Edo University Iyamho. The primary station has an elevation of about $45 \mathrm{~m}$ above sea level. Its location provided by coordinate $7.15174{ }^{\circ} \mathrm{N}$ and $6.30098{ }^{\circ} \mathrm{E}$. The experiment is modelled as shown in Figure 2. Remote Station 1 (the Control Station) is located at the Administrative building in the main campus of Edo University Iyamho. The control station has an elevation of about $188 \mathrm{~m}$ above sea level. The Remote Station 2 (the Test station) was deployed in an undulating landscape, located in Iyamho town). The elevation is $88 \mathrm{~m}$ above the sea level.

\subsection{Method of Data Collection}

Data collection was done using Wireshark 3.0.5 installed on all the participating computers. Connectivity between the base station and the two remote stations located $3 \mathrm{~km}$ away from the base station was continuously monitored. Packets from the two remote stations were captured simultaneously from April to September, 2019 over a period of 30 days during rainfall. The failure rates from the base station to the remote stations were recorded. The failure and success rates at which packets were received from both remote stations were recorded under the same weather conditions.

\subsection{Network Modelling}

The following tools were used for Network modelling and simulation: Huawei enterprise network simulation platform (eNSP); Huawei AP6510DN series wireless $5 \mathrm{GHz}$ radios, Huawei $\mathrm{S700}$ series switch, and a HP Probook. Figure 3 shows the topology of the model. A class $\mathrm{C}$ network with network address of 192.168.1.0 and subnet mask 255.255.255.0 was used. The base station is connected to highly efficient switch, while the other remote stations were connected directly to a HP Notebook of same specifications.

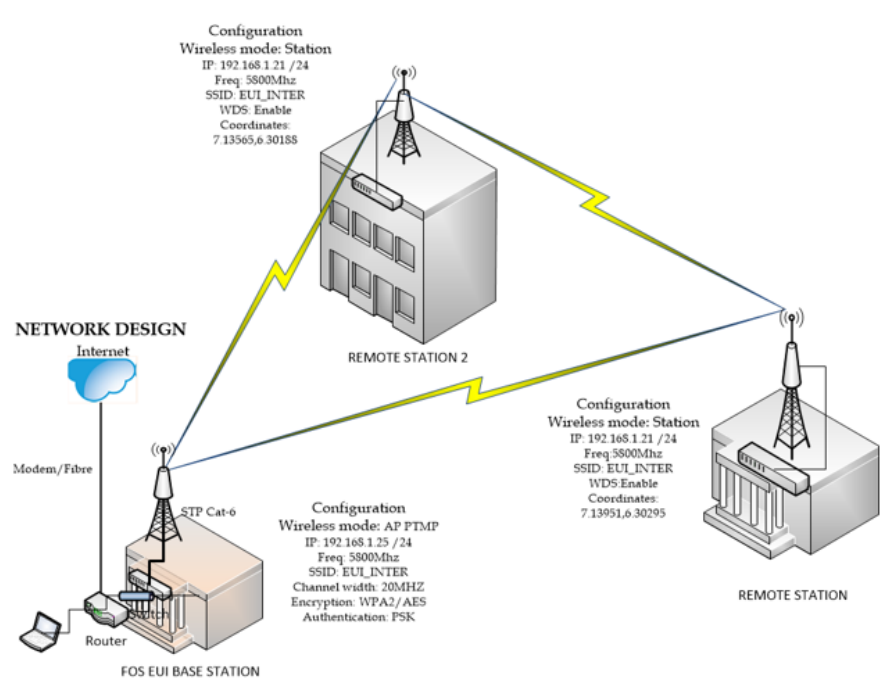

Figure 2: Diagrammatic Description of Experimental Design.

The essence of using same computer specification across the three locations was to ensure that no extraneous factors were introduced into the network in respect of performance [29]. Presumably, the use of same computer specification with same configuration and applications installed which are operating within same physical conditions would help ensure uniformity in performance.

Following the modelling, a 64k ping flood was sent from the BASE to the remote stations (REMOTE 1 and REMOTE 2) for three consecutive hours. The same ping flood was sent from the two remote access points to the BASE over same period. Wireshark was used to capture the frequency of the packets sent and the packets received.

\subsection{System Requirements and Physical Configuration}

The physical configuration involves coupling the Ubiquiti Rocket M5 radios together with the sector antennae which were positioned at the three locations. For the base station, a Huawei 


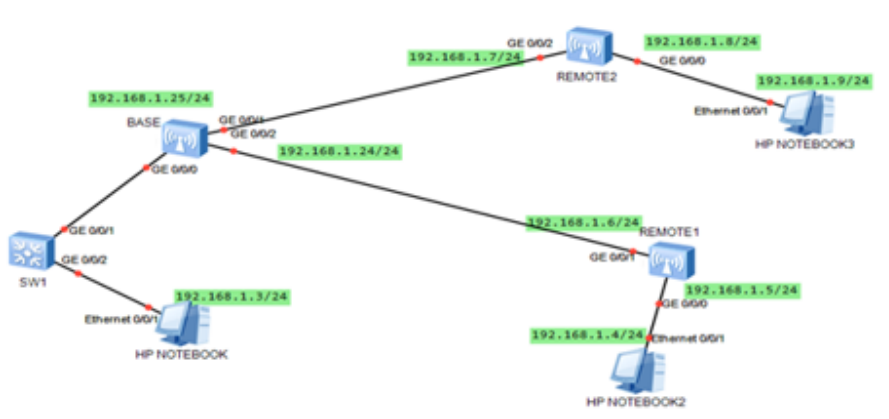

Figure 3: Topology of the Network.

S700 series switch was used to connect the HP notebook and the Access point. Figure 4-6 show the various configurations of the base station (BASE) and the remote stations (REMOTE 1 and REMOTE 2) respectively.

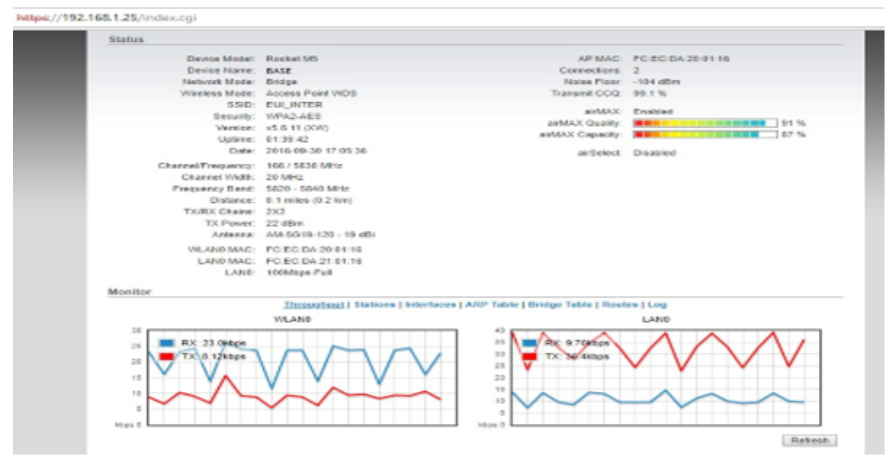

Figure 4: Configuration of the Base Station Radio.

\subsection{Data Capture with Wireshark}

As mentioned earlier, data capture on the physical network was done using wireshark installed on the three HP notebooks. Prior to capture on physical network, a simulation was done using eNSP and wireshark on one of the HP notebooks. The result of the simulation did not yield any departure as regards traffic sent to and packets received from the remote stations.

In the physical network, 64k frames were flooded to the remote stations from the base station for over a period of 30 days rainy period. It should be noted that the period was only during the rainy cloudy weather.

\section{Results and Discussion}

Table 1 to 6 show the statistics of the packets relayed and received by the base station from the remote stations. Note that the remote stations are tagged; REMOTE 1 and REMOTE 2. As previously stated, we used REMOTE 1 as a control station while REMOTE 2 was the test station.

Figure 7 shows the comparative analysis of the packet losses to both Remote 1 and Remote 2. On the other hand, Figure 8 shows the relationship between the duration of rainfall and packet losses. The charts are created using data from Table 5.

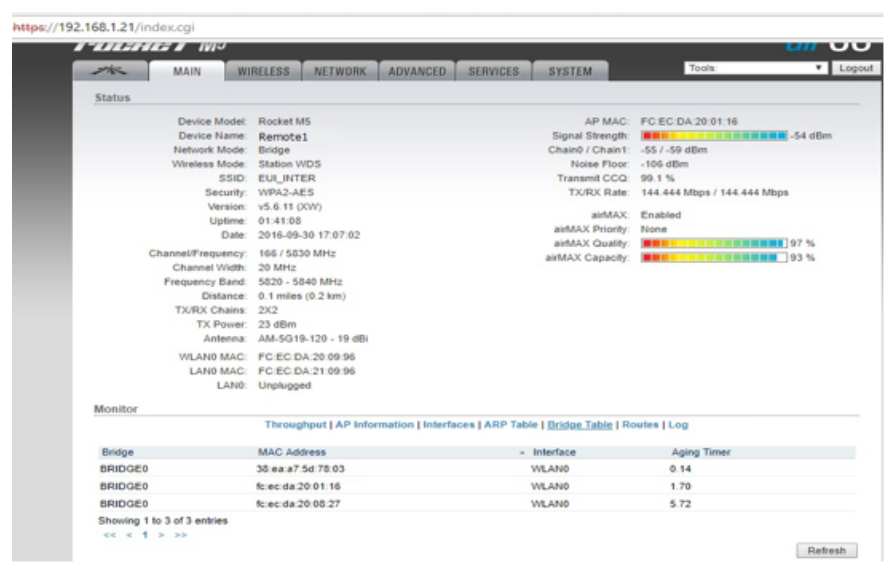

Figure 5: Configuration of the Control Radio (Remote 1).

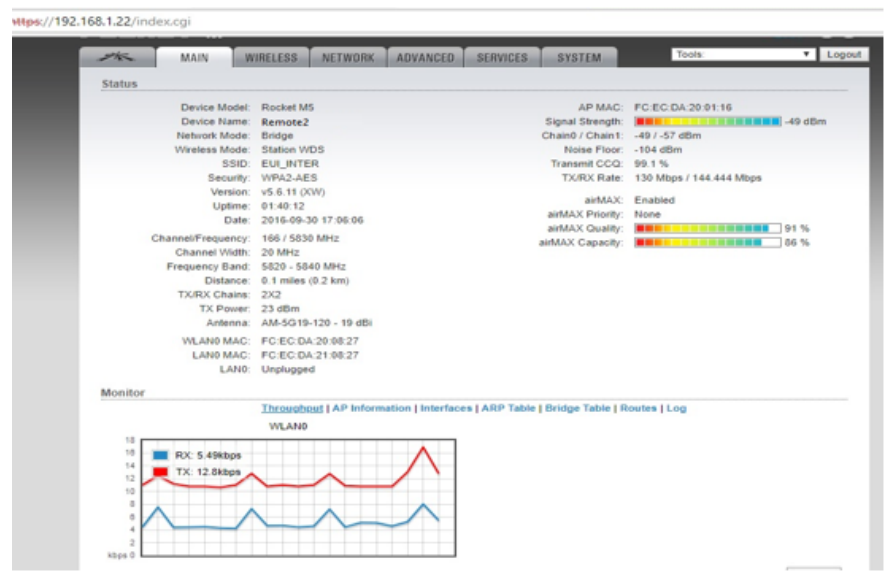

Figure 6: Configuration of the Test Radio (Remote 2).

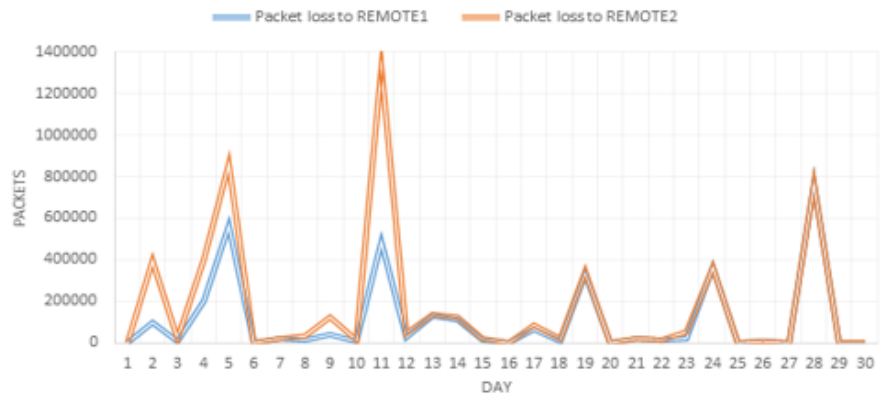

Figure 7: Comparative Analysis of Packet Losses from Base Station to Remote Stations.

Figure 9 shows a stacked area chart. The area chart summarized the relationship between the lost frames at both Remote 1 and Remote 2 respectively.

In this experiment, three radios were used. The base station was used as the reference point to coordinate the point to multipoint connections. Two remote stations were employed with one as the control radio and the second as the test radio. From the charts in Figures 7-9, it is evident that regardless of the duration of rainfall or cloudy weather conditions, data losses across the radio located on undulating paths are higher than that located on plane paths. It may be submitted that notwithstanding 
Table 1: Traffic States on Base Station .

\begin{tabular}{|c|c|c|c|}
\hline Day & Period of Rainfall (Minutes) & Packets Sent from Base to REMOTE 1 & Packets Received from REMOTE 1 \\
\hline 1 & 15 & 7005 & 5600 \\
\hline 2 & 55 & 3575000 & 3479154 \\
\hline 3 & 23 & 112876 & 102876 \\
\hline 4 & 18 & 926547 & 725467 \\
\hline 5 & 75 & 2367234 & 1803467 \\
\hline 6 & 10 & 2136 & 1159 \\
\hline 7 & 33 & 82345 & 61234 \\
\hline 8 & 46 & 234654 & 223456 \\
\hline 9 & 32 & 436788 & 394659 \\
\hline 10 & 16 & 64763 & 59874 \\
\hline 11 & 42 & 2348765 & 1863534 \\
\hline 12 & 26 & 104566 & 80001 \\
\hline 13 & 31 & 934525 & 802211 \\
\hline 14 & 22 & 932442 & 823426 \\
\hline 15 & 39 & 120001 & 103736 \\
\hline 16 & 4 & 2034 & 1108 \\
\hline 17 & 18 & 789686 & 723456 \\
\hline 18 & 34 & 100870 & 90711 \\
\hline 19 & 53 & 2346000 & 2012664 \\
\hline 20 & 8 & 1264 & 1023 \\
\hline 21 & 24 & 109827 & 90736 \\
\hline 22 & 24 & 101453 & 90534 \\
\hline 23 & 21 & 204332 & 183454 \\
\hline 24 & 32 & 2364758 & 2002374 \\
\hline 25 & 13 & 23487 & 21763 \\
\hline 26 & 23 & 102876 & 98234 \\
\hline 27 & 10 & 1726 & 1407 \\
\hline 28 & 22 & 841234 & 80023 \\
\hline 29 & 13 & 2305 & 1600 \\
\hline 30 & 11 & 1656 & 1432 \\
\hline
\end{tabular}


Table 2: Traffic on Base Station Computer.

\begin{tabular}{lccc}
\hline Day & Period of Rainfall (Minutes) & Packets Sent from Base to REMOTE 2 & Packets Received from REMOTE 2 \\
\hline 1 & 15 & 7005 & 4600 \\
2 & 55 & 3575000 & 3179152 \\
3 & 23 & 112876 & 92176 \\
4 & 18 & 926547 & 525167 \\
5 & 75 & 2367234 & 1503467 \\
6 & 10 & 2136 & 1102 \\
7 & 33 & 82345 & 60024 \\
8 & 46 & 234654 & 200856 \\
9 & 32 & 436788 & 312259 \\
10 & 16 & 64763 & 50174 \\
11 & 42 & 2348765 & 1023434 \\
12 & 26 & 104566 & 60020 \\
13 & 31 & 934525 & 801241 \\
14 & 22 & 932442 & 811606 \\
15 & 39 & 120001 & 100123 \\
16 & 4 & 2034 & 1003 \\
17 & 18 & 789686 & 702356 \\
18 & 34 & 100870 & 80034 \\
19 & 53 & 2346000 & 2002344 \\
20 & 8 & 1264 & 0865 \\
21 & 24 & 109827 & 90502 \\
22 & 24 & 101453 & 89534 \\
23 & 21 & 204332 & 153454 \\
24 & 32 & 2364758 & 2001234 \\
25 & 13 & 23487 & 21456 \\
26 & 23 & 102876 & 98234 \\
27 & 10 & 1726 & 959 \\
28 & 22 & 841234 & 80023 \\
29 & 13 & 2305 & 1200 \\
30 & 11 & 1656 & 1325 \\
\hline & & & \\
\hline
\end{tabular}


Table 3: Traffic from REMOTE 1 to Base Station.

\begin{tabular}{lccc}
\hline Day & Rainfall Time (minutes) & Packets Received by BASE & Packets Sent to BASE Station \\
\hline 1 & 15 & 5523 & 5600 \\
2 & 55 & 3455000 & 3479154 \\
3 & 23 & 100876 & 102876 \\
4 & 18 & 700547 & 725467 \\
5 & 75 & 1727234 & 1803467 \\
6 & 10 & 1140 & 1159 \\
7 & 33 & 61200 & 61234 \\
8 & 46 & 200654 & 223456 \\
9 & 32 & 380788 & 394659 \\
10 & 16 & 57763 & 59874 \\
11 & 42 & 1858765 & 1863534 \\
12 & 26 & 78956 & 80001 \\
13 & 31 & 800525 & 802211 \\
14 & 22 & 800442 & 823426 \\
15 & 39 & 100001 & 103736 \\
16 & 4 & 1100 & 1108 \\
17 & 18 & 700686 & 723456 \\
18 & 34 & 89487 & 90711 \\
19 & 53 & 1986000 & 2012664 \\
20 & 8 & 980 & 1023 \\
21 & 24 & 889827 & 90736 \\
22 & 24 & 90045 & 90534 \\
23 & 21 & 180332 & 183454 \\
24 & 32 & 1934758 & 2002374 \\
25 & 13 & 19487 & 21763 \\
26 & 23 & 92876 & 98234 \\
27 & 10 & 1200 & 1407 \\
28 & 22 & 789234 & 80023 \\
29 & 13 & 1400 & 1600 \\
30 & 11 & 1043 & 1432 \\
\hline & & &
\end{tabular}


Table 4: Traffic from REMOTE2 to BASE Station.

\begin{tabular}{lccc}
\hline Days & Rainfall Time (minutes) & Packets Received by BASE Station & Packets Sent to BASE Station \\
\hline 1 & 15 & 4002 & 4600 \\
2 & 55 & 3375000 & 3179152 \\
3 & 23 & 75876 & 92176 \\
4 & 18 & 486547 & 525167 \\
5 & 75 & 1367234 & 1503467 \\
6 & 10 & 950 & 1102 \\
7 & 33 & 59345 & 60024 \\
8 & 46 & 194654 & 200856 \\
9 & 32 & 296788 & 312259 \\
10 & 16 & 44763 & 50174 \\
11 & 42 & 164876 & 1023434 \\
12 & 26 & 50456 & 60020 \\
13 & 31 & 724525 & 801241 \\
14 & 22 & 782442 & 811606 \\
15 & 39 & 90080 & 100123 \\
16 & 4 & 950 & 1003 \\
17 & 18 & 659686 & 702356 \\
18 & 34 & 73387 & 80034 \\
19 & 53 & 1896000 & 2002344 \\
20 & 8 & 820 & 0865 \\
21 & 24 & 88582 & 90502 \\
22 & 24 & 80245 & 89534 \\
23 & 21 & 162332 & 153454 \\
24 & 32 & 1834758 & 2001234 \\
25 & 13 & 18487 & 21456 \\
26 & 23 & 92876 & 98234 \\
27 & 10 & 800 & 959 \\
28 & 22 & 72123 & 80023 \\
29 & 13 & 1105 & 1200 \\
30 & 11 & 1100 & 1325 \\
\hline & & &
\end{tabular}


Table 5: Statistics on Packets Losses to Remote Stations.

\begin{tabular}{|c|c|c|c|}
\hline Days & Rainfall Time (minutes) & Packet Loss to REMOTE 1 & Packet Loss to REMOTE 2 \\
\hline 1 & 15 & 1405 & 2405 \\
\hline 2 & 55 & 95846 & 395848 \\
\hline 3 & 23 & 10000 & 20700 \\
\hline 4 & 18 & 201080 & 401380 \\
\hline 5 & 75 & 563767 & 863767 \\
\hline 6 & 10 & 977 & 1034 \\
\hline 7 & 33 & 21111 & 22321 \\
\hline 8 & 46 & 11189 & 33798 \\
\hline 9 & 32 & 42129 & 124529 \\
\hline 10 & 16 & 4889 & 14589 \\
\hline 11 & 42 & 485231 & 1325331 \\
\hline 12 & 26 & 24565 & 44546 \\
\hline 13 & 31 & 132314 & 133284 \\
\hline 14 & 22 & 109016 & 120836 \\
\hline 15 & 39 & 16265 & 19878 \\
\hline 16 & 4 & 926 & 1031 \\
\hline 17 & 18 & 66230 & 87330 \\
\hline 18 & 34 & 10159 & 20836 \\
\hline 19 & 53 & 333336 & 343656 \\
\hline 20 & 8 & 241 & 399 \\
\hline 21 & 24 & 19091 & 19325 \\
\hline 22 & 24 & 10919 & 11919 \\
\hline 23 & 21 & 20878 & 50878 \\
\hline 24 & 32 & 362384 & 363524 \\
\hline 25 & 13 & 1724 & 2031 \\
\hline 26 & 23 & 4642 & 4642 \\
\hline 27 & 10 & 319 & 767 \\
\hline 28 & 22 & 761211 & 761211 \\
\hline 29 & 13 & 705 & 1105 \\
\hline 30 & 11 & 224 & 331 \\
\hline
\end{tabular}


Table 6: Statistics on Packet Delivery to Remote Stations.

\begin{tabular}{|c|c|c|c|c|}
\hline Days & Rainfall Time (Minutes) & Packet Sent & Packet Received by Remote 1 & Packet Received by Remote 2 \\
\hline 1 & 15 & 7005 & 5600 & 4600 \\
\hline 2 & 55 & 3575000 & 3479154 & 3179152 \\
\hline 3 & 23 & 112876 & 102876 & 92176 \\
\hline 4 & 18 & 926547 & 725467 & 525167 \\
\hline 5 & 75 & 2367234 & 1803467 & 1503467 \\
\hline 6 & 10 & 2136 & 1159 & 1102 \\
\hline 7 & 33 & 82345 & 61234 & 60024 \\
\hline 8 & 46 & 234654 & 223456 & 200856 \\
\hline 9 & 32 & 436788 & 394659 & 312259 \\
\hline 10 & 16 & 64763 & 59874 & 50174 \\
\hline 11 & 42 & 2348765 & 1863534 & 1023434 \\
\hline 12 & 26 & 104566 & 80001 & 60020 \\
\hline 13 & 31 & 934525 & 802211 & 801241 \\
\hline 14 & 22 & 932442 & 823426 & 811606 \\
\hline 15 & 39 & 120001 & 103736 & 100123 \\
\hline 16 & 4 & 2034 & 1108 & 1003 \\
\hline 17 & 18 & 789686 & 723456 & 702356 \\
\hline 18 & 34 & 100870 & 90711 & 80034 \\
\hline 19 & 53 & 2346000 & 2012664 & 2002344 \\
\hline 20 & 8 & 1264 & 1023 & 0865 \\
\hline 21 & 24 & 109827 & 90736 & 90502 \\
\hline 22 & 24 & 101453 & 90534 & 89534 \\
\hline 23 & 21 & 204332 & 183454 & 153454 \\
\hline 24 & 32 & 2364758 & 2002374 & 2001234 \\
\hline 25 & 13 & 23487 & 21763 & 21456 \\
\hline 26 & 23 & 102876 & 98234 & 88234 \\
\hline 27 & 10 & 1726 & 1407 & 959 \\
\hline 28 & 22 & 841234 & 80023 & 80023 \\
\hline 29 & 13 & 2305 & 1600 & 1200 \\
\hline 30 & 11 & 1656 & 1432 & 1325 \\
\hline
\end{tabular}




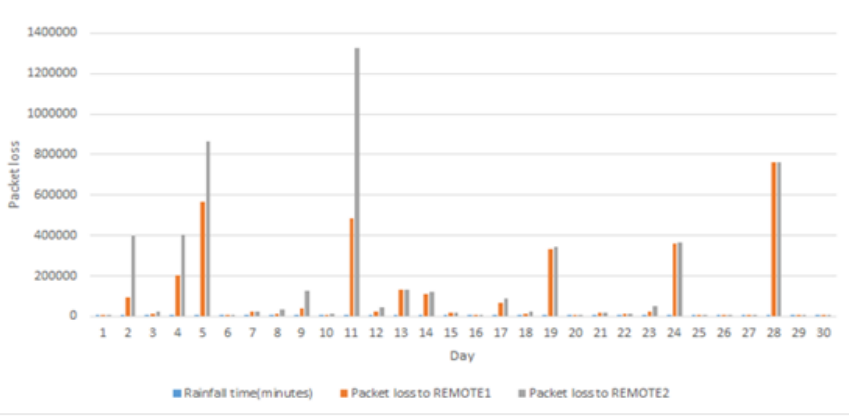

Figure 8: Relationship between Duration of Rainfall and Packet Losses to Remote Stations.

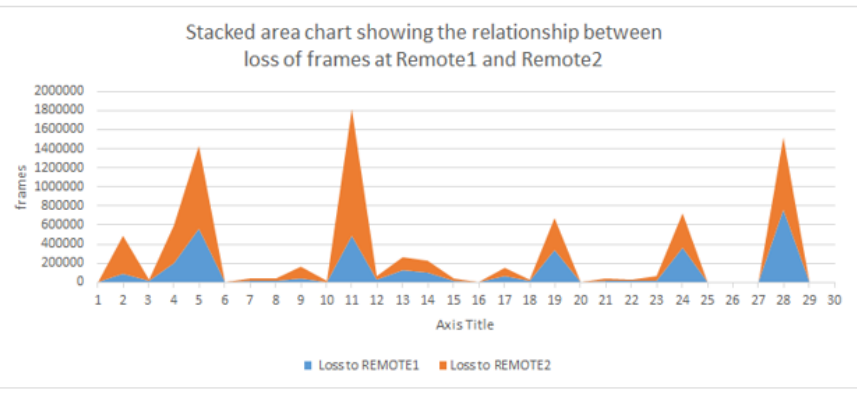

Figure 9: Stacked Area Chart Showing the relationship between Lost Frames from the two Remote Stations.

the line of sight existing between two geographically located radios, the impact of rainfall is very likely to intensify when radios are placed on terrains with highly undulating surfaces.

\section{Conclusion}

Following the data capture and subsequent statistical analysis, we have made the following conclusions:

i. Signal strength and propagation of $5 \mathrm{GHz}$ radios placed on undulating terrains are severely affected by deteriorating or adverse weather conditions.

ii. Though the cause of the manifest deviation obtained are not very clear, it appears that signal losses are attributed to interference caused by rainfall owing to high relative humidity, amplified by possible bias introduced by the undulating terrains.

iii. Future studies are to take into consideration more meteorological variables, over a long period of time in order to have more beneficial and comprehensive results.

\section{Acknowledgments}

We thank the referees for the positive enlightening comments and suggestions, which have greatly helped us in making improvements to this paper.

\section{References}

[1] G. R. Maurya, P. A. Kokate, S. K. Lokhande \& J. A. Shrawankar J. A, "A Review on Investigation and Assessment of Path Loss Models in Urban and Rural Environment", IOP Conf. Ser.: Mater. Sci. Eng. 225 (2017) 012219.

[2] K. E. Ukhurebor, M. S. Maor \& E. E. Aigbe "Mollification of WCDMA Interference on Uplink Channels in Cellular Network Using the Power Control Approach”, British Journal of Applied Science \& Technology, 20 (2017) 1.

[3] B. Y. Lawal, K. E. Ukhurebor, M. A. Adekoya \& E. E. Aigbe "Quality of Service and Performance Analysis of A GSM Network in Eagle Square, Abuja and Its Environs, Nigeria", International Journal of Scientific \& Engineering Research, 7 (2016) 1992.

[4] D. Y. Choi, J. Y. Pyun, S. K. Noh \& S. W. Lee "Comparison of Measured Rain Attenuation in the $12.25 \mathrm{GHz}$ Band with Prediction by the ITUR Model", International Journal of Antennas and Propagation, 415398 (2012) 1 .

[5] L. A. R Da Silva Mello, M. S. Pontes, R. M. de Souza \& N. A. PérezGarcía "Prediction of Rain Attenuation in Terrestrial Links using Full Rainfall Rate Distribution", Electronics Letters, 43 (2007) 1442.

[6] J. W. F. Goddard "Propagation in Rain and Cloud Spatial Temporal Structures of Rain. In: Propagation of Radio Waves", (2nd ed) UK, IEE, London (2013).

[7] J. S. Ojo, M. O. Ajewole \& S. K. Sarkar "Rain Rate and Rain Attenuation Prediction for Satellite Communication in $\mathrm{Ku}$ and $\mathrm{Ka}$ Bands over Nigeria”, Progress in Electromagnetic Research B, 5 (2008) 207.

[8] A. Y. Abdulrahman, T. A. Rahman, S. K. A. Rahim \& M. R. U. Islam "A New Rain Attenuation Conversion Technique for Tropical Regions", Progress in Electromagnetics Research B, 26 (2010) 53.

[9] U. Siddique, L. Ahmad L \& G. Raja "Microwave Attenuation and Prediction of Rain Outage for Wireless Networks in Pakistan's Tropical Region”, International Journal of Microwave Science and Technology, 14927 (2011) 1.

[10] Y. S. Meng \& Y. H. Lee "Investigations of Foliage Effect on Modern Wireless Communication Systems: A Review", Progress in Electromagnetics Research, 105 (2010) 313.

[11] G. N. Ezeh, N.S. Chukwuneke, N.C. Ogujiofor \& U.H. Diala U.H "Effects of Rain Attenuation on Satellite Communication Link.", Advances in Science and Technology Research Journal, 8 (2014) 1.

[12] M. C. Kestwal, S. Joshi \& L. S. Garia "Prediction of Rain Attenuation and Impact of Rain in Wave Propagation at Microwave Frequency for Tropical Region (Uttarakhand, India)", International Journal of Microwave Science and Technology, 958498 (2014) 1.

[13] K. E. Ukhurebor, S. O. Azi, I. C. Abiodun \& E. Enoyoze "Approximation of the Dew Point Temperature Using a Cost-Effective Weather Monitoring System", Physical Science International Journal, 14 (2017) 1.

[14] K. E. Ukhurebor, T. B. Batubo, I. C. Abiodun \& E. Enoyoze "The Influence of Air Temperature on the Dew Point Temperature in Benin City, Nigeria”, Journal for Applied Science and Environmental Management, 21 (2017) 657.

[15] K. E. Ukhurebor, I. C. Abiodun \& F. Bakare "Relationship between Relative Humidity and the Dew Point Temperature in Benin City, Nigeria", Journal for Applied Science and Environmental Management, 21 (2017) 953.

[16] K. E. Ukhurebor \& S. O. Azi "Review of Methodology to Obtain Parameters for Radio Wave Propagation at Low Altitudes from Meteorological Data: New Results for Auchi Area in Edo State, Nigeria", Journal of King Saud University - Science, https://doi.org/10.1016/j.jksus.2018.03.001 (2018).

[17] K. E. Ukhurebor, S. O. Azi, I. C. Abiodun \& S. E. Ojiemudia "The Influence of Weather Variables on Atmospheric Refractivity over Auchi, South-South, Nigeria", Journal for Applied Science and Environmental Management, 22 (2018) 471.

[18] K. E. Ukhurebor \& I. Odesanya "Relationship between Meteorological Variables and Effective Earth Radius Factor over Auchi, Edo State, SouthSouth, Nigeria", Covenant Journal of Physical \& Life Sciences, 7 (2019) 1.

[19] M. Hashim \& S. Stavrou "Measurements and Modelling of Wind Influence on Radiowave Propagation through Vegetation" IEEE Transactions on Wireless Communications, 5 (2006) 1055. 
[20] S. Perras \& L. Bouchard "Fading Characteristics of RF Signals due to Foliage in Frequency Bands from 2 to $60 \mathrm{GHz}$ ", The 5th International and Symposium Wireless Personal Multimedia Communications, (2002) 1.

[21] E. R. Pelet, J. E. Salt \& G. Wells "Effect of Wind on Foliage Obstructed Line-of-Sight Channel at $2.5 \mathrm{GHz}$ ", IEEE Trans. Broadcast, 50 (2004) 224.

[22] J. C. R. Dal Bello, L. S. Glaucio \& L. B. Henry "Theoretical Analysis and Measurement Results of Vegetation Effects on Path Loss for Mobile Cellular Communication Systems", IEEE Transactions on Vehicular Technology 49 (2000).

[23] I. Cuin̄as, A.V. Alejos, M.G. Sánchez \& R.F.S. Caldeirinha "Wind Effect on the Scattering from Vegetation at Cellular Phone Frequencies", Proceedings of the IEEE International Geoscience \& Remote Sensing Symposium, IGARSS Barcelona, Spain (2007).

[24] M. Zennaro, H. Ntareme \& A. Bagula "Experimental Evaluation of Temporal and Energy Characteristics of an Outdoor Sensor Network", Proceedings of the International Conference on Mobile Technology, Applications, and Systems, 99 (2008).
[25] J. Zhao \& R. Govindan "Understanding Packet Delivery Performance in Dense Wireless Sensor", Proceedings of the 1st International Conference on Embedded Networked Sensor Systems, Los Angeles, California, USA (2003).

[26] D. Puccinelli \& M. Haenggi "Multipath Fading in Wireless Sensor Networks: Measurements and Interpretation", Proceedings of the International Conference on Wireless Communications and Mobile Computing, Vancouver, British Columbia, Canada (2006).

[27] K. E. Ukhurebor K. E, S. A. Olayinka, W. Nwankwo \& C. Alhasan "Evaluation of the Effects of some Weather Variables on UHF and VHF Receivers within Benin City, South-South Region of Nigeria", Journal of Physics: IOP Conference Series. 1299 (2019) 012052.

[28] K. E. Ukhurebor \& O. J. Umukoro "Influence of Meteorological Variables on UHF Radio Signal: Recent Findings for EBS, Benin City, SouthSouth, Nigeria”, IOP Conference Series: Earth \& Environment Science, 173 (2018) 012017.

[29] ECC Report 192 "The Current Status of Dynamic Frequency Selection (DFS) In the $5 \mathrm{GHz}$ Frequency Range", (2014). 